\title{
BMJ Open Use of biologics during pregnancy and risk of serious infections in the mother and baby: a Canadian population-based cohort study
}

\author{
Nicole W Tsao, ${ }^{1}$ Larry D Lynd, ${ }^{1,2}$ Eric C Sayre, ${ }^{3}$ Mohsen Sadatsafavi, ${ }^{1}$ \\ Gillian Hanley, ${ }^{4}$ Mary A De Vera ${ }^{1}$
}

To cite: Tsao NW, Lynd LD, Sayre EC, et al. Use of biologics during pregnancy and risk of serious infections in the mother and baby: a Canadian population-based cohort study. BMJ Open 2019;9:e023714. doi:10.1136/ bmjopen-2018-023714

- Prepublication history and additional material for this paper are available online. To view these files, please visit the journal online (http://dx.doi org/10.1136/bmjopen-2017023714).

Received 20 April 2018 Revised 6 December 2018 Accepted 10 December 2018

Check for updates

(C) Author(s) (or their employer(s)) 2019. Re-use permitted under CC BY-NC. No commercial re-use. See rights and permissions. Published by BMJ.

${ }^{1}$ Faculty of Pharmaceutical Sciences, University of British Columbia, Vancouver, British Columbia, Canada

${ }^{2}$ Centre for Health Evaluation and Outcomes Sciences, Vancouver, British Columbia, Canada

${ }^{3}$ Arthritis Research Canada, Richmond, British Columbia, Canada

${ }^{4}$ Department of Obstetrics \& Gynaecology, University of British Columbia, Vancouver, British Columbia, Canada

Correspondence to

Dr Mary A De Vera;

mdevera@mail.ubc.ca

\section{ABSTRACT}

Objectives To investigate the association between exposure to biologics during pregnancy and serious infections in mothers and infants.

Design Retrospective cohort study.

Setting Population-based.

Participants Women with one or more autoimmune diseases identified by International Classification of Diseases 9th/10th revision codes in healthcare administrative databases in British Columbia, Canada, who had pregnancies ending in a live or stillbirth between 1 January 2002 and 31 December 2012. Women were defined as exposed if they had at least one biologic prescription during pregnancy, and infants born to these women were considered exposed in utero. Diseasematched women with no biologics prescriptions during pregnancy, and their infants, comprised the unexposed groups. Primary outcome measures Serious infections requiring hospitalisation.

Results Over the 10-year study period, there were 6218 women (8607 pregnancies) who had an autoimmune disease diagnosis, of which 90 women were exposed to biologics during pregnancy, with 100 babies born to these women. Among women exposed to biologics during pregnancy, occurrence of serious postpartum infections were low, ranging from $0 \%$ to $5 \%$, depending on concomitant exposures to immunosuppressants. In multivariable models using logistic regression, the $\mathrm{OR}$ for the association of biologics exposure with serious maternal postpartum infections was 0.79 (95\% Cl 0.24 to 2.54). In infants exposed to biologics in utero, occurrence of serious infections during the first year of life ranged from $0 \%$ to $7 \%$, depending on concomitant exposures to immunosuppressants in utero. Multivariable models showed no association between biologics exposure in utero and serious infant infections (OR $0.56,95 \% \mathrm{Cl} 0.17$ to 1.81 ). Conclusions These population-based data suggest that the use of biologics by women with autoimmune diseases during pregnancy is not associated with an increased risk of serious infections in mothers, during post partum or in infants during the first year of life.

\section{INTRODUCTION}

Biologics have revolutionised the management of several autoimmune chronic conditions, and are commonly used in
Strengths and limitations of this study

- This is the first population-based cohort study to examine the risk of serious postpartum infections in mothers who were using biologics during pregnancy, and in infants exposed in utero.

- We used individual-level, deidentified, longitudinal data on all health services (physician visits, hospitalisations and prescription medications) covering the entire population of the province, linked with a perinatal registry covering $>99 \%$ of births.

- We used high-dimensional propensity score matching as a sensitivity analysis to the traditional multivariable models.

- The data sources come from administrative databases not primarily collected for research purposes and thus rely on accuracy of diagnostic coding.

- Exposures and outcomes remain relatively rare and, as such, caution should be exercised when interpreting the findings in light of this context.

inflammatory arthritis including rheumatoid arthritis (RA), ankylosing spondylitis (AS), psoriatic arthritis (PsA) as well as inflammatory bowel disease (IBD, ulcerative colitis and Crohn's disease). ${ }^{12}$ They are typically genetically engineered parts of, or whole, immunoglobulin Gs (IgG) that inhibit specific components of the immune system that play pivotal roles in inflammation. ${ }^{3}$ Despite their established effectiveness in managing autoimmune diseases, treatment with biologics is not without risks. Network meta-analyses show a significant increase in serious infections in patients with RA treated with biologics alone (OR 1.31; 95\% credible interval 1.09 to 1.58 ) or in combination with traditional disease modifying antirheumatic drugs (DMARDs) (OR 1.34; $95 \%$ CI 1.09 to 1.69 ) compared with DMARDs alone. ${ }^{4}$

In pregnancy, infection risk is a unique safety outcome in that it can occur both in the mother and her infant possibly as a result of 
exposure to the same offending agent. Additionally, the risk of infections may already be elevated for the mother during the delivery and postpartum periods, and for the neonate after birth when their immune system is still naive. During pregnancy, IgG is transferred from the maternal to the fetal circulation by receptor-mediated binding of the Fc $\gamma$ portion of the IgG molecule and its receptor, FcRn (Fc receptor neonatal) ${ }^{5-7} \mathrm{FcRn}$ is also found to have a protective effect on IgG degradation, extending its lifespan, leading to accumulation in the infant for upwards of 6 to 8 months. ${ }^{8}$ With infliximab and adalimumab having higher affinity for FcRn, ${ }^{9}$ levels of these biologics in offspring cord blood have been reported to be $300 \%-400 \%$ higher than levels in the maternal circulation. ${ }^{10}$ Furthermore, detectable, and even therapeutic, levels of biologics in infant serum have been confirmed in case reports of infants exposed in utero. ${ }^{10-12}$ However, to date, few epidemiological studies have examined the risk of infections in women using biologics during pregnancy, or in infants that were exposed to biologics in utero. Our objectives were to investigate the association between exposure to biologics during pregnancy and serious infections in (1) mothers during the postpartum period and (2) infants during the first year of life.

\section{METHODS}

\section{Data sources}

Data for mothers and babies were obtained through Population Data BC, a repository of individual-level, deidentified, longitudinal data on all health services covering the entire population of $\mathrm{BC}$ (estimated 4.6 million residents, December $2016^{13}$ ). Specifically, respective data for mothers and babies comprised four linked databases including: (1) Medical Services Plan (MSP) database-all provincially funded physician visits, ordered laboratory tests and diagnostic procedures (X-rays, ultrasounds, etc) ${ }^{14}$; (2) Discharge Abstract Database (DAD) -all hospital admissions and discharges ${ }^{15}$; (3) PharmaNet-a comprehensive prescription drug database that captures all prescriptions dispensed in community pharmacies regardless of payment source, since $1996^{16}$; and (4) BC Perinatal Database Registry (BCPDR) -facilitated the linkage between mothers' and babies' data. The BCPDR contains data abstracted from obstetrical and neonatal medical records on nearly $100 \%$ of births in the province of $\mathrm{BC}$ from over 60 acute care facilities as well as births occurring at home attended by $\mathrm{BC}$ registered midwives, including women who had pregnancies ending in a live or stillbirth of at least 20 weeks gestation or $500 \mathrm{~g}$ birth weight. ${ }^{17-20}$ Details of these data sources are described in previous work ${ }^{21}$ and databases and linkages are shown in figure 1.

\section{Study cohort}

The source population comprised women in BC who had pregnancies ending in a live or stillbirth between 1 January 2002 and 31 December 2012, and were continuously covered by BC's provincial health plan for at least 12 months prior to the start of pregnancy and in the 12 months following delivery. This requirement of continuous insurance coverage ensures that we have complete data capture for all women and babies in our study population. We created a cohort of women from the source

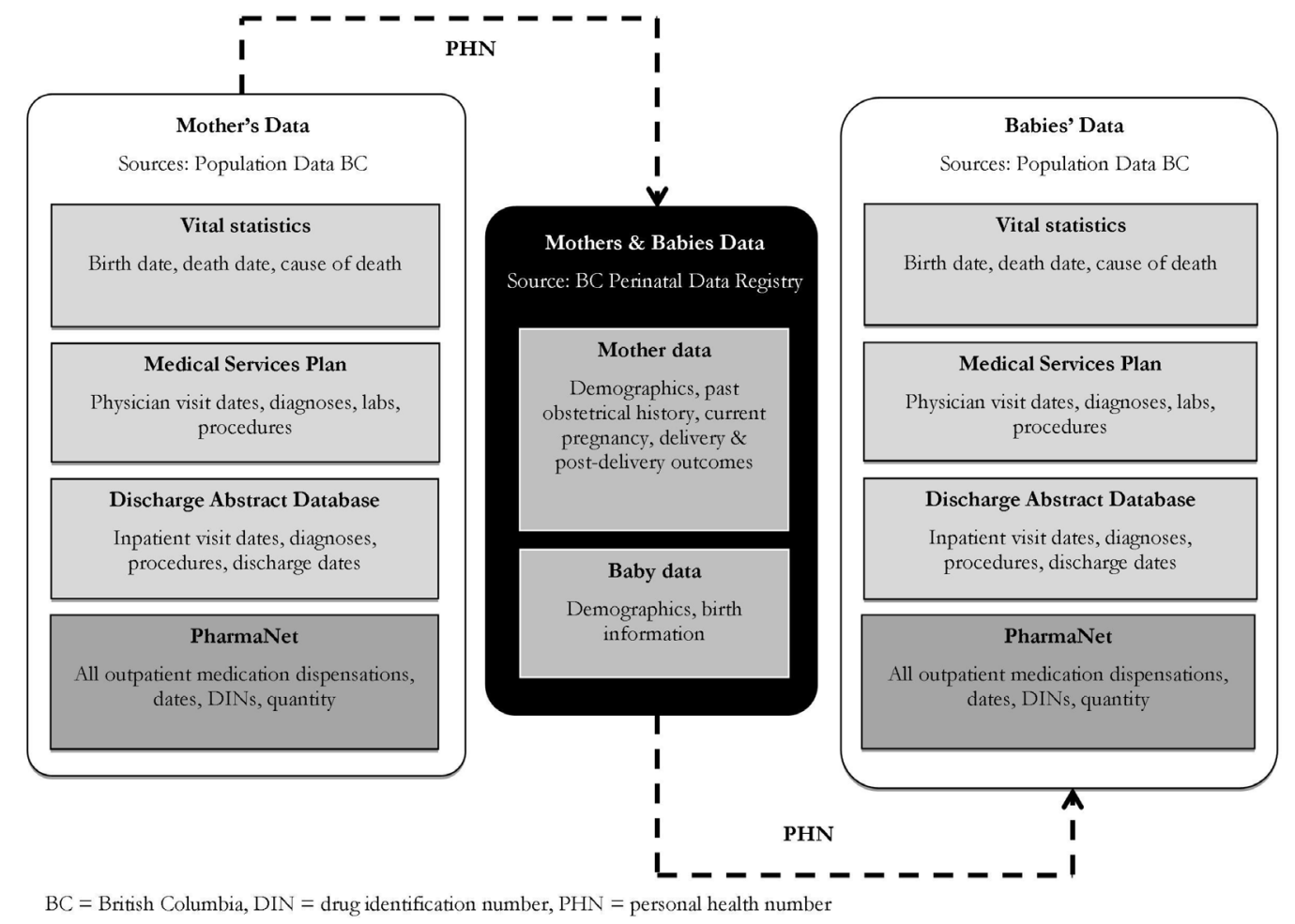

Figure 1 Schematic diagram of databases and linkages facilitating study analyses. 
population who had a recorded diagnosis of one or more autoimmune diseases that could be treated with a biologic, including RA, IBD (Crohn's disease and ulcerative colitis), psoriasis (Ps)/PsA, AS, juvenile idiopathic arthritis and systemic autoimmune rheumatic diseases. Women were considered to have been diagnosed with one of these conditions if they had the same International Classification of Diseases (ICD)-9th revision or 10th revision codes for a specific autoimmune disease from two separate physician visits that were at least 60 days apart and within 2 years, any time prior to the date of conception, or having at least one hospitalisation with an ICD-9/10 code for an autoimmune disease any time prior to the date of conception. ${ }^{21}$ Given that the unit of analysis was individual pregnancy, each pregnancy had to satisfy the above criteria in order to be included in the analyses. All singleton live born infants from these pregnancies were included in the analyses of infant serious infections.

\section{Biologics exposure}

Using dispensation dates and Canadian Drug Identity Codes for biologics in PharmaNet linked with date of conception and date of delivery of each pregnancy in the BCPDR, exposure to biologics was identified in any woman in the autoimmune disease cohort with one or more prescriptions for a biologic anytime from the date of conception to the date of delivery. ${ }^{21}$ Infants born from these pregnancies were classified as being exposed to biologics in utero. Pregnancies that did not satisfy this criteria and infants born from those pregnancies were considered unexposed. All biologics available in BC for the treatment of autoimmune diseases of interest during the study period, along with concomitant medications considered in this study, are listed in online supplementary table S1.

\section{Serious infections}

The outcomes of interest were serious infections requiring hospitalisation during the postpartum period in women, and serious infections requiring hospitalisation anytime during the first year of life in infants. Serious postpartum infections were defined as any episode of hospitalisation, including the delivery episode, with one or more ICD-9/10 codes for an infection anytime from the date of delivery until 42 days post partum-the conventional definition for postpartum period of concern. ${ }^{22}$ Serious infections in infants were defined as any episode of hospitalisation with one or more ICD-9/10 codes for an infection anytime during the first year of life-due to the lengthy accumulation of biologics in infant circulationor until death, whichever occurred first. All infections considered are listed in online supplementary table S2.

\section{Covariates}

All covariates considered were from the aforementioned data sources. Maternal factors included characteristics of current pregnancy, prior obstetrical history, comorbidities and medication use. Characteristics of current pregnancy
Table 1 Characteristics of moms and infants in pregnancies exposed and unexposed to biologics

\begin{tabular}{|c|c|c|c|}
\hline $\begin{array}{l}\text { Maternal } \\
\text { characteristics }\end{array}$ & $\begin{array}{l}\text { Biologic } \\
\text { exposed }\end{array}$ & $\begin{array}{l}\text { Biologic } \\
\text { unexposed }\end{array}$ & P value? \\
\hline \multicolumn{4}{|l|}{ Current pregnancy } \\
\hline $\begin{array}{l}\text { Maternal age at } \\
\text { delivery (mean (SD)) }\end{array}$ & $31.0(4.7)$ & $31.2(5.2)$ & 0.657 \\
\hline Multiparous & $44(44 \%)$ & $4998(59 \%)$ & 0.003 \\
\hline $\begin{array}{l}\text { Antenatal visits (mean } \\
\text { (SD)) }\end{array}$ & $8.9(3.6)$ & $9.0(3.9)$ & 0.749 \\
\hline $\begin{array}{l}\text { Gestational } \\
\text { hypertension }\end{array}$ & $5(5 \%)$ & $647(8 \%)$ & 0.328 \\
\hline Gestational diabetes & $12(12 \%)$ & $669(8 \%)$ & 0.128 \\
\hline $\begin{array}{l}\text { Delivery via caesarean } \\
\text { section }\end{array}$ & $40(40 \%)$ & $2849(33 \%)$ & 0.171 \\
\hline
\end{tabular}

Neighbourhood

income quintiles

\begin{tabular}{|c|c|c|c|}
\hline 5th percentile & $21(21 \%)$ & $1763(21 \%)$ & 0.836 \\
\hline 25th percentile & $24(24 \%)$ & $1699(20 \%)$ & \\
\hline $\begin{array}{l}\text { Median (50th } \\
\text { percentile) }\end{array}$ & 17 (17\%) & $1845(22 \%)$ & \\
\hline 75th percentile & $22(22 \%)$ & $1803(21 \%)$ & \\
\hline 95th percentile & $16(16 \%)$ & 1397 (16\%) & \\
\hline $\begin{array}{l}\text { Hospitalisation at } \\
\text { baseline }\end{array}$ & 99 (99\%) & 8412 (99\%) & 0.912 \\
\hline $\begin{array}{l}\text { BMI at baseline (mean } \\
\text { (SD)) }\end{array}$ & $24.7(4.6)$ & $24.6(4.5)$ & 0.867 \\
\hline
\end{tabular}

BMI categories

$\begin{array}{llll}\text { Obese } & 9(9 \%) & 851(10 \%) & 0.979 \\ \text { Overweight } & 15(15 \%) & 1342(16 \%) & \end{array}$

Prior obstetrical

history

$\begin{array}{llll}\text { Premature delivery } & 5(5 \%) & 500(6 \%) & 0.711 \\ \text { Spontaneous abortion } & 28(28 \%) & 2230(26 \%) & 0.686 \\ \text { Delivery with neonatal } & <5^{\star} & 52(0.6 \%) & 0.621\end{array}$

death

$\begin{array}{llll}\text { Stillbirth } & <5^{\star} & 103(1 \%) & 0.107 \\ \text { Low birthweight infant } & 5(5 \%) & 243(3 \%) & 0.203 \\ \text { Infant with anomalies } & 0(0 \%) & 74(1 \%) & 0.349\end{array}$

Autoimmune disease

type†

\begin{tabular}{|c|c|c|c|}
\hline $\begin{array}{l}\text { Inflammatory bowel } \\
\text { disease }\end{array}$ & $50(50 \%)$ & 2471 (29\%) & $<0.001$ \\
\hline Rheumatoid arthritis & $44(44 \%)$ & $1756(21 \%)$ & $<0.001$ \\
\hline $\begin{array}{l}\text { Psoriasis/psoriatic } \\
\text { arthritis }\end{array}$ & $16(16 \%)$ & $3441(40 \%)$ & $<0.001$ \\
\hline $\begin{array}{l}\text { Juvenile idiopathic } \\
\text { arthritis }\end{array}$ & $8(8 \%)$ & $93(1 \%)$ & $<0.001$ \\
\hline $\begin{array}{l}\text { Systemic autoimmune } \\
\text { rheumatic diseases }\end{array}$ & $5(5 \%)$ & 1063 (12\%) & 0.024 \\
\hline Ankylosing spondylitis & $5(5 \%)$ & 417 (5\%) & 0.964 \\
\hline
\end{tabular}

Continued 
Table 1 Continued

\begin{tabular}{|c|c|c|c|}
\hline $\begin{array}{l}\text { Maternal } \\
\text { characteristics }\end{array}$ & $\begin{array}{l}\text { Biologic } \\
\text { exposed }\end{array}$ & $\begin{array}{l}\text { Biologic } \\
\text { unexposed }\end{array}$ & P valueף \\
\hline \multicolumn{4}{|l|}{ Biologicsł } \\
\hline Infliximab & $54(54 \%)$ & & \\
\hline Etanercept & $41(41 \%)$ & & \\
\hline Adalimumab & 39 (39\%) & & \\
\hline Other biologic§ & $18(18 \%)$ & & \\
\hline
\end{tabular}

Concomitant

medications

\begin{tabular}{|c|c|c|c|}
\hline DMARDs & $53(53 \%)$ & $1843(22 \%)$ & $<0.001$ \\
\hline Glucocorticoids & $54(54 \%)$ & $1065(13 \%)$ & $<0.001$ \\
\hline Traditional NSAIDs & $16(16 \%)$ & $941(11 \%)$ & 0.118 \\
\hline Antidepressants & $16(16 \%)$ & $783(9 \%)$ & 0.020 \\
\hline Anxiolytics & $<5^{\star}$ & $394(5 \%)$ & 0.765 \\
\hline COX2 NSAIDs & $<5^{\star}$ & $56(0.7 \%)$ & $<0.001$ \\
\hline \multicolumn{4}{|l|}{ Comorbidities } \\
\hline Anxiety & $19(19 \%)$ & $1368(16 \%)$ & 0.430 \\
\hline Mood disorders & $10(10 \%)$ & $432(5 \%)$ & 0.027 \\
\hline Asthma & $<5^{\star}$ & $154(2 \%)$ & 0.888 \\
\hline Diabetes & $<5^{\star}$ & $563(6.6 \%)$ & 0.294 \\
\hline Hypertension & $6(6 \%)$ & $975(11.5 \%)$ & 0.088 \\
\hline Infant characteristics & $\begin{array}{l}\text { Biologic } \\
\text { exposed }\end{array}$ & $\begin{array}{l}\text { Biologic } \\
\text { unexposed }\end{array}$ & \\
\hline Female sex & $55(55 \%)$ & $4159(49 \%)$ & 0.224 \\
\hline $\begin{array}{l}\text { Gestational age (mean } \\
\text { (SD)) }\end{array}$ & $\begin{array}{l}37.8 \text { weeks } \\
(2.4)\end{array}$ & $\begin{array}{l}38.4 \text { weeks } \\
(2.2)\end{array}$ & 0.004 \\
\hline $\begin{array}{l}\text { Birth weight (mean } \\
\text { (SD)) }\end{array}$ & $\begin{array}{l}3158 \mathrm{~g} \\
(634)\end{array}$ & 3385 g (204) & $<0.001$ \\
\hline $\begin{array}{l}\text { Apgar score at } 1 \mathrm{~min} \\
\text { (mean (SD)) }\end{array}$ & $8.1(1.6)$ & $8.0(1.7)$ & 0.730 \\
\hline $\begin{array}{l}\text { Apgar score at } 5 \mathrm{~min} \\
\text { (mean (SD)) }\end{array}$ & $8.9(1.1)$ & $9.0(1.0)$ & 0.595 \\
\hline
\end{tabular}

*All cell sizes $<5$ are suppressed due to privacy restrictions of data sharing agreements.

†Sum of percentages exceed $100 \%$ due to some individuals having more than one diagnosis.

$\ddagger$ Sum of percentages exceed $100 \%$ due to some pregnancies being exposed to more than one drug.

§Other biologics include: abatacept, alefacept, certolizumab pegol, golimumab, rituximab, tocilizumab and ustekinumab.

IP values based on t-tests or $\chi^{2}$ tests.

BMI, body mass index; COX, cyclooxygenase; DMARDs, diseasemodifying antirheumatic drugs; NSAIDs, non-steroidal antiinflammatory drugs.

included maternal age at delivery (continuous), parity (primiparous or multiparous), neighbourhood income quintile (based on postal code) at baseline, body mass index (BMI) at first antenatal visit (continuous; and categorical as underweight: $<18.5$, normal: 18.5-24.9, overweight: $25-29.9$, obese: $\left.\geq 30 \mathrm{~kg} / \mathrm{m}^{2}\right)$, weight gain during pregnancy (binary, based on guidelines for weight gain during pregnancy by BMI category ${ }^{23}$ ), number of antenatal visits (continuous) and hospitalisation at baseline (binary) and delivery by caesarean section (binary). Prior obstetrical history included binary outcomes from previous pregnancies (if applicable) including premature delivery, spontaneous abortions, neonatal death, stillbirth, low birth weight and congenital anomalies. Comorbidities considered included gestational hypertension, gestational diabetes, anxiety disorders, mood disorders, asthma, hypertension and diabetes. Concomitant medications included DMARDs or immunosuppressants, glucocorticoids, antidepressants, anxiolytics, traditional and COX-2 non-steroidal anti-inflammatory drugs (NSAIDs). All maternal factors considered in analyses of postpartum infections in the mother that could be associated with serious infections in infants were also considered in analyses of this latter outcome in addition to infant characteristics. Infant characteristics included sex and Apgar scores at $1 \mathrm{~min}, 5 \mathrm{~min}$ and $10 \mathrm{~min}$ (continuous). Other infant characteristics including gestational age, birth weight and presence of anomalies were considered but not included in the analysis as they may be possible mediators of the effect of exposure on serious infections in infants.

\section{Statistical analysis}

Using logistic regression models we calculated ORs with 95\% CIs between maternal exposure to biologics during pregnancy and the risk of serious postpartum infections in women, and the risk of serious infant infections during the first year of life, first as unadjusted models, by treatment categories only (model 1 ) and then adjusted for maternal and infant characteristics according to respective outcome (model 2). Multivariable models were constructed using forward selection and covariates were included in the final models if they were associated with the exposure in bivariate analyses and resulted in lower Akaike information criterion on inclusion. Multivariable regression analyses using generalised estimating equation models with logit link and clustered by mother could not be completed as models did not converge. However, previous work on a larger sample from our source population showed that accounting for correlations between multiple pregnancies within the same woman did not appreciably change effect estimates and CI. ${ }^{21}$

As a sensitivity analysis, we estimated propensity for biologics exposure in each pregnancy using a high-dimensional propensity score (HDPS) algorithm that incorporated investigator-specified covariates and additional factors that acted as proxy variables for unmeasured confounders from the four aforementioned data dimensions (model 3).$^{24}$ These variables included use of medications (eg, DMARDs, glucocorticoids), comorbidities (eg, depression) and healthcare utilisation (eg, outpatient visits, prenatal care and tests and investigations). The HDPS was calculated using logistic regression then each biologic exposed pregnancy was matched with five unexposed pregnancies (1:5 ratio) without replacement, based on HDPS, whereby an unexposed pregnancy may only be 


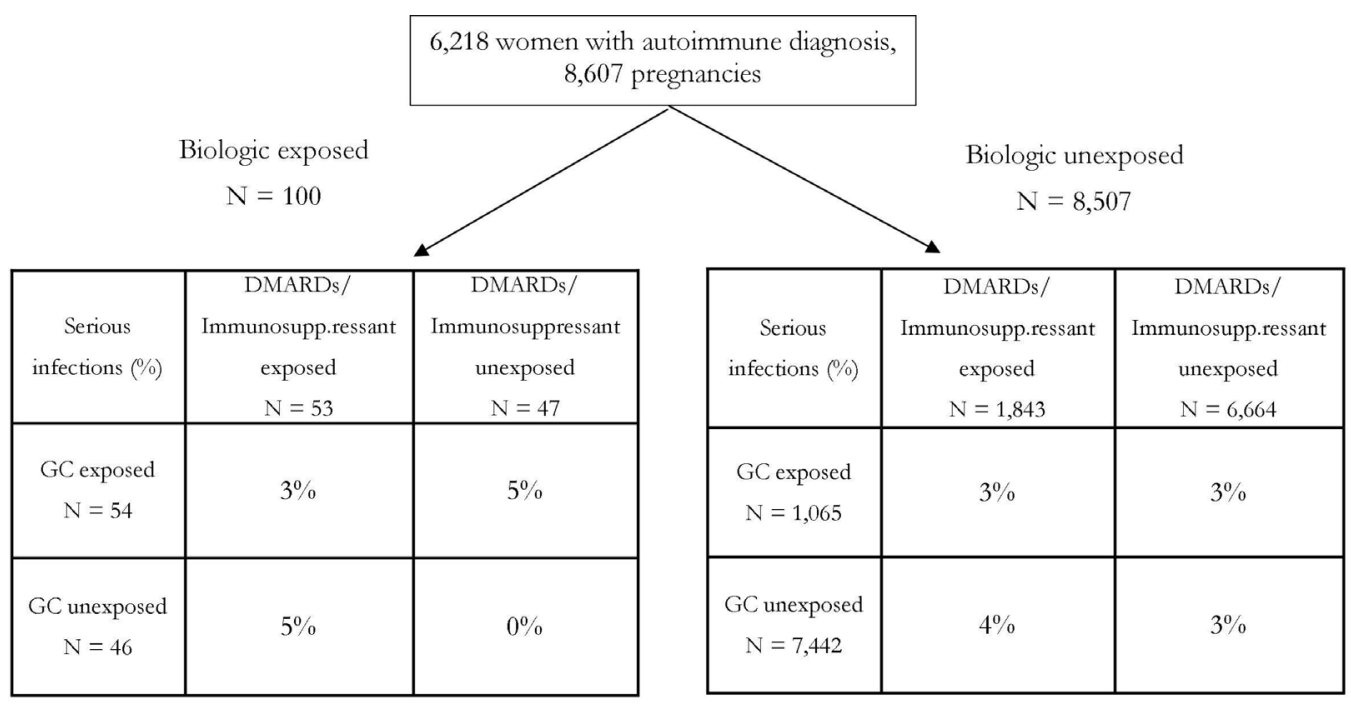

DMARDs = disease modifying anti-rheumatic drugs, GC = glucocorticoids

Figure 2 Rates of maternal postpartum serious infections based on drug exposure categories.

used once as a match. Match performance was evaluated by comparing the standardised mean differences in baseline characteristics of matched and unmatched cohorts. OR and 95\% CIs for biologics exposure and serious postpartum infections, and serious infant infections were calculated using logistic regression in the HDPS-matched

Table 2 Risk of serious maternal postpartum infections associated with biologics exposure during pregnancy

\begin{tabular}{|c|c|c|}
\hline \multicolumn{3}{|c|}{ Maternal serious infections } \\
\hline & Parameter & OR $(95 \% \mathrm{Cl})$ \\
\hline Unadjusted & Biologics & 0.90 (0.28 to 2.84$)$ \\
\hline \multirow[t]{3}{*}{ Model 1} & Biologics & 0.88 (0.27 to 2.82$)$ \\
\hline & $\begin{array}{l}\text { DMARDs/ } \\
\text { immunosuppressants }\end{array}$ & 0.98 (0.68 to 1.40$)$ \\
\hline & Glucocorticoids & $1.07(0.64$ to 1.77$)$ \\
\hline \multirow[t]{8}{*}{ Model 2} & Biologics & 0.79 (0.24 to 2.54$)$ \\
\hline & $\begin{array}{l}\text { DMARDs/ } \\
\text { immunosuppressants }\end{array}$ & 0.98 (0.68 to 1.40$)$ \\
\hline & Glucocorticoids & $1.00(0.60$ to 1.67$)$ \\
\hline & Multiparity & $0.60(0.47$ to 0.76$)$ \\
\hline & Anxiety & 1.36 (1.02 to 1.82$)$ \\
\hline & Prior hospital admissions & 1.19 (1.06 to 1.34$)$ \\
\hline & BMI at baseline & $1.02(1.00$ to 1.05$)$ \\
\hline & $\begin{array}{l}\text { Caesarean section } \\
\text { delivery }\end{array}$ & 2.01 (1.58 to 2.55$)$ \\
\hline $\begin{array}{l}\text { Model } 3 \\
\text { HDPS- } \\
\text { matched } \\
\text { cohort }\end{array}$ & Biologics & $1.16(0.34$ to 4.14$)$ \\
\hline
\end{tabular}

BMI, body mass index; DMARDs, disease-modifying antirheumatic drugs; HDPS, high-dimensional propensity score. samples. All analyses were conducted using SAS statistical software V.9.3 (Cary, North Carolina, USA).

\section{Study conduct}

This study was approved by the University of British Columbia, Behavioural Research Ethics Board. All inferences, opinions and conclusions drawn in this manuscript are those of the authors, and do not reflect the opinions or policies of the data stewards. Due to data sharing agreements and confidentiality, cell sizes of less than five individuals are not reported.

\section{Patient and public involvement}

Patients were not involved in the design, recruitment or conduct of the study as this is a retrospective cohort study using population-wide administrative data.

\section{RESULTS}

In the cohort of 6218 women with autoimmune inflammatory disease diagnoses and 8607 singleton pregnancies, there were 90 women exposed to biologics during pregnancy, and 100 babies born to these women. As shown in table 1, in the biologics exposed group, more women had IBD or RA, used at least one DMARD or glucocorticoid, or had mood disorders; whereas in the group not exposed to biologics during pregnancy, more women had Ps/PsA and were multiparous. Also shown in table 1, infants from pregnancies that were unexposed to biologics had more advanced gestational age and higher birth weight.

Among women exposed to biologics during pregnancy, occurrence of serious postpartum infections were rare, ranging from $0 \%$ to $5 \%$, depending on concomitant exposures to DMARDs or glucocorticoids (figure 2). Serious infections that occurred in those exposed to biologics included infection of the amniotic sac and membranes, and bacterial puerperal infections. In model 1 looking 


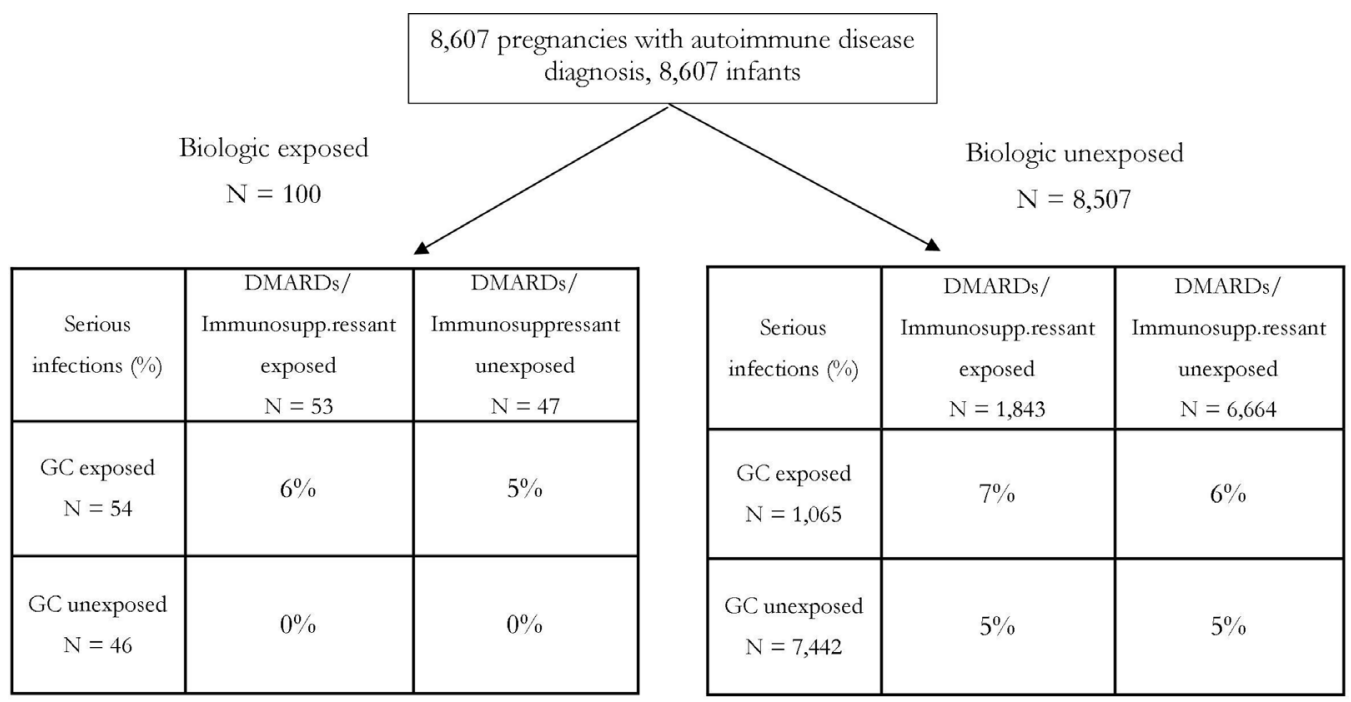

DMARDs = disease modifying anti-rheumatic drugs, GC = glucocorticoids

Figure 3 Rates of infant serious infections during the first year of life based on in utero drug exposure categories.

only at drug exposures, we found no independent associations between the use of biologics (OR 0.88, 95\% CI 0.27 to 2.82 ), DMARDs (OR $0.98,95 \%$ CI 0.68 to 1.40 ) or glucocorticoids (OR 1.07, 95\% CI 0.64 to 1.77 ), with the risk of serious postpartum infections (table 2). The results were similar when maternal factors were included (model 2); specifically, the association between biologics exposure and serious postpartum infections had an OR of 0.79 (95\% CI 0.24 to 2.54), DMARD/immunosuppressants had an OR of 0.98 (95\% CI 0.68 to 1.40 ) and glucocorticoids had an OR of 1.00 (95\% CI 0.60 to 1.67) (table 2). In this model, we also found several independent maternal factors that were significantly associated with either increased or decreased postpartum infections; having an anxiety diagnosis, more previous hospitalisations, higher BMI at conception and delivering via caesarean section were all factors that increased the risk of serious infection, while being multiparous appeared protective. Results from sensitivity analysis using HDPSmatching and logistic regression had higher uncertainty due to a wide CI (model 3).

In infants exposed to biologics in utero, proportion of serious infections ranged from $0 \%$ to $7 \%$ depending on the treatment combination used by the mother during pregnancy (figure 3 ). The types of serious infections that occurred during infants' first year of life were lymphadenitis, urinary tract infection and acute bronchiolitis. In model 1 examining categories of maternal drug exposures only, we found no increased risk of serious infections in infants who were exposed to biologics (OR 0.50, $95 \% \mathrm{CI} 0.16$ to 1.60 ), or DMARDs (OR $1.07,95 \% \mathrm{CI}$ 0.81 to 1.43 ) in utero, while glucocorticoids exposure appeared to possibly increase risk (OR 1.46, 95\% CI 1.00 to 2.12). When maternal and infant factors were considered (model 2), the risk of serious infections associated with biologics exposure had an OR of 0.56 (95\% CI 0.17 to 1.81), DMARD/immunosuppressants had an OR of 1.09
(95\% CI 0.81 to 1.45 ) and glucocorticoids had an OR of 1.13 (95\% CI 0.77 to 1.66) (table 3). However, we found several maternal factors associated with an increased risk of infections in infants, including multiparity, maternal history of prior delivery resulting in a low birthweight infant, or premature infant, maternal use of anxiolytics and maternal asthma diagnosis (table 3). Factors associated with a lower risk of serious infections included being a female infant, having higher Apgar score at $1 \mathrm{~min}$, higher neighbourhood income and more antenatal visits. Sensitivity analysis using logistic regression in the HDPSmatched cohort did not change these results (model 3).

\section{DISCUSSION}

In this study using linked administrative health data and a perinatal registry for a population-based cohort of women with autoimmune disease and their babies, we examined the association between exposure to biologics during pregnancy and risk of serious infections in mothers and infants, respectively. Specifically for mothers, these were infections requiring hospitalisation during the postpartum period; and for infants, these were infections requiring hospitalisation during their first year of life. We found that the proportion of serious infections in all groups was low. Our findings suggest that there was no difference in risk of serious postpartum infections in women who used biologics during pregnancy versus those who did not. Similarly, we did not observe a difference in risk of serious infections during the first year of life in infants born to mothers who used biologics during pregnancy compared with those who did not. While we examined all biologics used in the cohort, TNF-alpha inhibitor biologics (94\%) were the most common, and as such, our results mostly apply to these biologics and less so to those that are not TNF-alpha inhibitors. 
Table 3 Risk of serious infant infections during the first year of life associated with biologics exposure in utero

\begin{tabular}{|c|c|c|}
\hline \multicolumn{3}{|c|}{ Infant serious infections } \\
\hline & Parameter & OR $(95 \% \mathrm{Cl})$ \\
\hline Unadjusted & Biologics & $0.58(0.18$ to 1.85$)$ \\
\hline \multirow[t]{3}{*}{ Model 1} & Biologics & $0.50(0.16$ to 1.60$)$ \\
\hline & $\begin{array}{l}\text { DMARDs/ } \\
\text { immunosuppressants }\end{array}$ & $1.07(0.81$ to 1.43$)$ \\
\hline & Glucocorticoids & 1.46 (1.00 to 2.12$)$ \\
\hline \multirow[t]{15}{*}{ Model 2} & Biologics & 0.56 (0.17 to 1.81$)$ \\
\hline & $\begin{array}{l}\text { DMARDs/ } \\
\text { immunosuppressants }\end{array}$ & 1.09 (0.81 to 1.45$)$ \\
\hline & Glucocorticoids & $1.13(0.77$ to 1.66$)$ \\
\hline & Female sex & 0.73 (0.60 to 0.89$)$ \\
\hline & Multiparity & 1.56 (1.25 to 1.95$)$ \\
\hline & Maternal antenatal visits & 0.97 (0.94 to 0.99$)$ \\
\hline & $\begin{array}{l}\text { Prior delivery with } \\
\text { anomaly }\end{array}$ & 2.04 (0.98 to 4.26$)$ \\
\hline & $\begin{array}{l}\text { Prior delivery with } \\
\text { low birth weight }\end{array}$ & $1.67(1.05$ to 2.64$)$ \\
\hline & Prior premature delivery & 1.73 (1.21 to 2.47$)$ \\
\hline & $\begin{array}{l}\text { Maternal antidepressant } \\
\text { use }\end{array}$ & $1.30(0.97$ to 1.75$)$ \\
\hline & Maternal anxiolytics use & 1.66 (1.15 to 2.40$)$ \\
\hline & $\begin{array}{l}\text { Maternal rheumatoid } \\
\text { arthritis diagnosis }\end{array}$ & 1.17 (0.93 to 1.47$)$ \\
\hline & $\begin{array}{l}\text { Maternal asthma } \\
\text { diagnosis }\end{array}$ & 2.00 (1.18 to 3.39$)$ \\
\hline & Apgar score at $1 \mathrm{~min}$ & 0.87 (0.83 to 0.92$)$ \\
\hline & $\begin{array}{l}\text { Neighbourhood income } \\
\text { quintile }\end{array}$ & 0.91 (0.85 to 0.98$)$ \\
\hline $\begin{array}{l}\text { Model } 3 \\
\text { HDPS-matched } \\
\text { cohort }\end{array}$ & Biologics & 0.49 (0.15 to 1.62$)$ \\
\hline
\end{tabular}

DMARDs, disease-modifying antirheumatic drugs; HDPS, highdimensional propensity score.

Indeed, serious infections are a well-known safety outcome in patients using biologics to manage their autoimmune diseases, and despite pregnant women and infants being vulnerable populations, there has been a dearth of evidence on this clinically important topic. One population-based study in the USA by Desai $e t$ al compared serious intrapartum infections among 776 users of biologics compared with 1587 users of non-biologics and reported no meaningful increase risk of serious infection during pregnancy (adjusted HR (aHR) $1.36,95 \%$ CI 0.47 to 3.93$).{ }^{25}$ However, the authors did observe that the rate of infections increased noticeably in all treatment groups as pregnancies approached term, ${ }^{25}$ thus providing a rationale for the objective of our study which examined the risk of infections around the time of childbirth, and post partum. No other studies to date have specifically investigated the association between biologics use and the risk of postpartum infections despite the fact that postpartum infections account for up to $10 \%$ of maternal deaths, and are a cause of shortterm morbidity and long-term complications. ${ }^{26}$ It is therefore reassuring that our study did not show an association between biologics use during pregnancy and maternal risk of postpartum infections.

Infections is a theoretical concern in infants exposed to biologics in utero, due to evidence of accumulation of certain biologics in cord blood. ${ }^{10}$ The immunosuppressive effect of TNF-alpha inhibitor accumulation is illustrated by a fatal case of disseminated Bacillus Calmette-Guérin (BCG) infection after BCG vaccination in an infant born to a mother treated with infliximab throughout her pregnancy. ${ }^{27}$ The infant received a BCG vaccination at 3 months of age, subsequently became ill and died at 4.5 months of age from disseminated infection. ${ }^{27}$ Current recommendations to stop some biologics in the third trimester are largely based on such case reports and expert opinion. ${ }^{28}$ To date, there have only been two published abstracts examining the association of biologics exposure and risk of serious infections in infants. Using data collected by the Organization of Teratology Information Specialists (OTIS), Chambers et al found similar proportions of serious infections during the first year of life in infants born to women with RA using biologics during pregnancy (2.8\%), compared with those born to women with RA not treated with a biologic $(3.9 \%)$, with a relative risk of 0.71 (95\% CI 0.30 to 1.71$){ }^{29}$ In a registry of women with IBD, Chaparro et al found that after a median follow-up of 33 months post partum, similarly, infants exposed to biologics in utero were not at greater risk of serious infections (HR $0.5,95 \% \mathrm{CI} 0.2$ to 1.3).$^{30}$ Our study is the first to corroborate these results using population-based data.

This study has a number of strengths and limitations. The use of population-wide databases with high coverage lends this study greater generalisability; linkages between databases containing valid information on all dispensed prescriptions (PharmaNet) and antenatal, intrapartum and postpartum maternal and infant information (BCPDR) provides the ability to accurately determine the timing of all medication dispensations with respect to conception dates. Linkages between maternal and infant data allow for ascertainment of infant exposure status in utero. Altogether, these strengths minimise potential biases caused by problems such as selection bias, patient recall bias, reporting bias and exposure misclassification.

The main limitation of our study stems from the uncertainty of risk estimates attributable to the relatively small sample size of the exposed; as such, a doubling to tripling in the risk of serious infections remains compatible with the upper bound of the CI of our estimates. With respect to exposure, while prescription dispensations does not necessarily equate to medication use, research by the EuroMAP Group has shown that pregnant women report taking $43 \%-50 \%$ of their prescribed medications, a level of medication adherence consistent with non-pregnant 
populations, and that adherence tends to be higher $(70 \%-100 \%)$ for drugs used in the treatment of chronic diseases in this population. ${ }^{31}$ Our previous study within the same cohort showed that the proportion of women discontinuing their biologic became larger as pregnancy progressed, resulting in fewer women being exposed close to delivery, which could be an explanation for the low numbers of outcomes observed in this study. ${ }^{21}$ Also due to the rare occurrence of the outcomes of interest, subgroup analyses of specific biologics, or specific autoimmune disease types were not possible. Other limitations included potential misclassification of the outcome, as a code for an infection could have been in any diagnostic field in the discharge abstract data and may not have been the primary reason for hospitalisation. Furthermore, we could not obtain any data on breastfeeding practices which has been shown to be protective against infections requiring hospitalisations ${ }^{32}$; other potentially important factors that were unavailable included maternal smoking status and alcohol or other substance use. However, our findings of other factors independently associated with serious infections, such as maternal $\mathrm{BMI},{ }^{33}$ caesarean section delivery, ${ }^{34}{ }^{35}$ infant gender ${ }^{36}$ and maternal asthma diagnosis, ${ }^{37}$ are consistent with that reported in the literature and thus lend validity to our results. Finally, although we used HDPS approaches in sensitivity analyses to address confounding by indication, an inherent limitation of administrative data, such as those used in our study, is that they do not provide clinical information to allow assessment of disease severity.

In conclusion, from this population-based cohort, we did not observe differences in the risk of serious infections in women using or not using TNF-alpha inhibitor biologics during pregnancies or in their offspring during the first year of life. Our findings are compatible with current recommendations where discontinuation of TNF-alpha inhibitor biologics late in the pregnancy could be considered, or if indicated, can be continued throughout the pregnancy. ${ }^{28} 38$ Our study provides information for clinicians and women with autoimmune diseases regarding the risks of serious infections when using biologics during pregnancy.

Acknowledgements The authors would like to thank Dr. Jeremy Rassen for his help in implementing the high-dimensional propensity score program.

Contributors Concept and design: MADV, NWT; acquisition, analysis and interpretation of data: MADV, NWT, ECS; drafting of manuscript: NWT, MADV; critical revision of manuscript for important intellectual content: NWT, MADV, MS, GH, LDL; statistical analysis: NWT, ECS; obtained funding: MADV.

Funding This research was funded by Arthritis Society Operating Grant (YIO-13-07) and Canadian Institutes of Health Research Operating Grant: Analyses of Existing Canadian Cohorts and Databases (A01-151540).

Disclaimer The funders had no part in the design, conduct or reporting of this study.

Competing interests LDL has received honoraria from Boehringer Ingelheim and Pfizer Canada for consulting services unrelated to this study. NWT is a Canadian Institutes of Health Research Fellowship holder. LDL is a Professor, and Director of Collaboration for Outcomes Research and Evaluation. ECS is a Research Associate and Statistician at Arthritis Research Canada. MS is an Assistant Professor, Canadian Institutes of Health Research New Investigator, and Michael Smith
Foundation for Health Research Scholar. GH is an Assistant Professor, Canadian Institutes of Health Research New Investigator, and a recipient of Canadian Cancer Society Research Institute Capacity Development Award. MADV is an Assistant Professor, Canada Research Chair in Medication Adherence, Utilization, and Outcomes, The Arthritis Society Network Scholar, and Michael Smith Foundation for Health Research Scholar.

Patient consent for publication Not required.

Provenance and peer review Not commissioned; externally peer reviewed.

Data sharing statement Due to privacy agreements, data used in this study cannot be shared.

Open access This is an open access article distributed in accordance with the Creative Commons Attribution Non Commercial (CC BY-NC 4.0) license, which permits others to distribute, remix, adapt, build upon this work non-commercially, and license their derivative works on different terms, provided the original work is properly cited, appropriate credit is given, any changes made indicated, and the use is non-commercial. See: http://creativecommons.org/licenses/by-nc/4.0/.

\section{REFERENCES}

1. Rosman Z, Shoenfeld Y, Zandman-Goddard G. Biologic therapy for autoimmune diseases: an update. BMC Med 2013;11:88.

2. Tiligada $\mathrm{E}$, Ishii $\mathrm{M}$, Riccardi $\mathrm{C}$, et al. The expanding role of immunopharmacology: IUPHAR Review 16. Br J Pharmacol 2015;172:4217-27.

3. Scott DL. Biologics-based therapy for the treatment of rheumatoid arthritis. Clin Pharmacol Ther 2012;91:30-43.

4. Singh JA, Cameron C, Noorbaloochi S, et al. Risk of serious infection in biological treatment of patients with rheumatoid arthritis: a systematic review and meta-analysis. The Lancet 2015;386:258-65.

5. Brambell FW. The transmission of immunity from mother to young and the catabolism of immunoglobulins. Lancet 1966;2:1087-93.

6. Wood GW, Bjerrum K, Johnson B. Detection of IgG bound within human trophoblast. J Immunol 1982;129:1479-84.

7. Kane SV, Acquah LA. Placental transport of immunoglobulins: a clinical review for gastroenterologists who prescribe therapeutic monoclonal antibodies to women during conception and pregnancy. Am J Gastroenterol 2009;104:228-33.

8. Junghans RP, Anderson CL. The protection receptor for IgG catabolism is the beta2-microglobulin-containing neonatal intestinal transport receptor. Proc Natl Acad Sci U S A 1996;93:5512-6.

9. Porter C, Armstrong-Fisher S, Kopotsha T, et al. Certolizumab pegol does not bind the neonatal Fc receptor (FcRn): Consequences for FcRn-mediated in vitro transcytosis and ex vivo human placental transfer. J Reprod Immunol 2016;116:7-12.

10. Soh MC, Nelson-Piercy C. High-risk pregnancy and the rheumatologist. Rheumatology 2015;54:572-87.

11. Vasiliauskas EA, Church JA, Silverman N, et al. Case report: evidence for transplacental transfer of maternally administered infliximab to the newborn. Clin Gastroenterol Hepatol 2006;4:1255-8.

12. Vinet E, Pineau C, Gordon C, et al. Biologic therapy and pregnancy outcomes in women with rheumatic diseases. Arthritis Rheum 2009;61:587-92.

13. Population Data BC. Population data bc: data linkage. $2016 \mathrm{https}: / /$ www.popdata.bc.ca/datalinkage.

14. Population Data BC. Data Extract. $\mathrm{MOH}$. British Columbia ministry of health (2013): medical services plan (msp) payment information file. $2014 \mathrm{http}: / /$ www.popdata.bc.ca/data.

15. Population Data BC. Data Extract. MOH. Canadian institute for health information (2013): discharge abstract database (hospital separations). 2014 http://www.popdata.bc.ca/data.

16. BC Ministry of Health. Data Extract. Data Stewardship Committee. BC ministry of health (2013): pharmaNet. 2014 http://www.popdata. bc.ca/data.

17. Population Data BC. Data Extract. BC Vital Statistics Agency. BC vital statistics agency (2012): vital statistics births. 2014 http://www. popdata.bc.ca/data.

18. Population Data BC. Data Extract. BC Vital Statistics Agency. BC vital statistics agency (2012): vital statistics stillbirths. $2014 \mathrm{http} / / /$ www.popdata.bc.ca/data.

19. Population Data BC. Data Extract. BC Vital Statistics Agency. BC Vital statistics agency (2013): vital statistics deaths. 2014 http://www. popdata.bc.ca/data.

20. Perinatal Services BCPopulation Data BC. Data Extract. PSBC. British Columbia perinatal data registry 2012. $2014 \mathrm{http}: / / \mathrm{www}$. perinatalservicesbc.ca/health-professionals/data-surveillance/ perinatal-data-registry. 
21. Tsao NW, Lynd LD, Sadatsafavi M, et al. Patterns of biologics utilization and discontinuation before and during pregnancy in women with autoimmune diseases: a population-based cohort study. Arthritis Care Res 2018;70:979-86.

22. Romano M, Cacciatore A, Giordano R, et al. Postpartum period: three distinct but continuous phases. J Prenat Med 2010;4:22-5.

23. Rasmussen KM, Catalano PM, Yaktine AL. New guidelines for weight gain during pregnancy: what obstetrician/gynecologists should know. Curr Opin Obstet Gynecol 2009;21:521-6.

24. Schneeweiss S, Rassen JA, Glynn RJ, et al. High-dimensional propensity score adjustment in studies of treatment effects using health care claims data. Epidemiology 2009;20:512-22.

25. Desai RJ, Bateman BT, Huybrechts KF, et al. Risk of serious infections associated with use of immunosuppressive agents in pregnant women with autoimmune inflammatory conditions: cohort study. BMJ 2017;356:j895.

26. Bonet M, Oladapo OT, Khan DN, et al. New WHO guidance on prevention and treatment of maternal peripartum infections. Lancet Glob Health 2015;3:e667-e668.

27. Cheent K, Nolan J, Shariq S, et al. Case Report: Fatal case of disseminated BCG infection in an infant born to a mother taking infliximab for Crohn's disease. J Crohns Colitis 2010;4:603-5

28. Flint J, Panchal S, Hurrell A, et al. BSR and BHPR guideline on prescribing drugs in pregnancy and breastfeeding-Part I: standard and biologic disease modifying anti-rheumatic drugs and corticosteroids. Rheumatology 2016;55:1693-7.

29. Chambers CD, Johnson DL, Luo Y, et al. Serious or Opportunistic Infections in Infants Born to Pregnant Women with Rheumatoid
Arthritis and Treated with a Biologic Medication. San Diego, CA: American College of Rheumatology Annual Meeting, 2017.

30. Chaparro M, Verreth A, Lobaton T, et al. Long-term safety of in utero exposure to anti-tnf $\alpha$ drugs for the treatment of inflammatory bowel disease: results from the multicenter european teddy study. Am J Gastroenterol 2018;113:396-403.

31. Olesen C, Søndergaard C, Thrane N, et al. Do pregnant women report use of dispensed medications? Epidemiology 2001;12:497-501.

32. Størdal K, Lundeby KM, Brantsæter AL, et al. Breast-feeding and infant hospitalization for infections: large cohort and sibling analysis. J Pediatr Gastroenterol Nutr 2017;65:225-31.

33. Axelsson D, Brynhildsen J, Blomberg M. Postpartum infection in relation to maternal characteristics, obstetric interventions and complications. J Perinat Med 2018;46:271-8.

34. Gibbs RS. Clinical risk factors for puerperal infection. Obstet Gynecol 1980;55:178S-83.

35. Yokoe DS, Christiansen CL, Johnson R, et al. Epidemiology of and surveillance for postpartum infections. Emerg Infect Dis 2001;7:837-41.

36. Muenchhoff M, Goulder PJ. Sex differences in pediatric infectious diseases. J Infect Dis 2014;209:S120-S126.

37. Carroll KN, Gebretsadik T, Minton P, et al. Influence of maternal asthma on the cause and severity of infant acute respiratory tract infections. J Allergy Clin Immunol 2012;129:1236-42.

38. Götestam Skorpen C, Hoeltzenbein M, Tincani A, et al. The EULAR points to consider for use of antirheumatic drugs before pregnancy, and during pregnancy and lactation. Ann Rheum Dis 2016;75:795-810. 